\title{
Improving the Sustainability of Office Partition Manufacturing: Balancing Options for Reducing Emissions of Volatile Organic Compounds
}

\author{
Frank S. Luisser and Marc A. Rosen *
}

Faculty of Engineering and Applied Science, University of Ontario Institute of Technology, 2000

Simcoe Street North, Oshawa, Ontario, L1H 7K4, Canada; E-Mail: fluisser@yahoo.com

* Author to whom correspondence should be addressed; E-mail: marc.rosen@uoit.ca;

Tel.: +1-905-721-8668; Fax: +1-905-721-3370

Received: 5 May 2009 / Accepted: 31 May 2009 / Published: 3 June 2009

\begin{abstract}
Options are examined to improve the sustainability of office partition manufacturing by reducing volatile organic compounds (VOC) emissions. Base VOC emissions for a typical plant are estimated using a mass balance approach. Pollution prevention and sustainability measures are assessed using realistic criteria and weightings. Sustainability has been considered from an industry perspective, considering factors like economics, environmental impact, quality, health and safety. Through a case study, it is demonstrated that several advantageous options are available for reducing VOC emissions in manufacturing office furniture partitions, and thereby enhancing the sustainability of that industrial operation. The measures deemed most viable include implementing several best management practices, not painting of non-visible parts, switching gluing processes, recycling solvent and modifying attachments. The results are intended to be balanced so as to improve their acceptability and adoptability by industry. It appears that it would be advantageous for manufacturers of office panels to evaluate the feasibility of these measures and to implement the most appropriate. The results are likely extendable to other operations in the wood furniture industry, and would improve their sustainability.
\end{abstract}

Keywords: sustainability; volatile organic compound; manufacturing; furniture; office partition; pollution; emissions 


\section{Introduction}

Sustainability has become an objective for many countries and citizens, for reasons such as environmental stewardship, economic equity and opportunity, social stability and others. Industry has traditionally often been focused on business sustainability, but now is increasingly seeking in various ways to make its operations and products more sustainable in a broader and more comprehensive sense. As a consequence, numerous measures to enhance sustainability have been proposed over the past few decades for products, systems and processes. These measures are often focused on reducing environmental emissions and impacts, but they are almost always also considered from other perspectives such as economic and social.

In industry, sustainability measures need to be balanced against each other as well as against factors not related to sustainability. Trade-offs are necessary because many of the sustainability measures oppose each other. Given industry's need to remain competitive, both locally and internationally, measured responses by industry are usually given to proposals to improve sustainability.

The need to carefully balance sustainability-improvement measures is particularly prevalent in manufacturing, which involves much of the activity of industry globally. The intense pressures felt by the manufacturing industry, as it undergoes fundamental restructuring in many jurisdictions and addresses factors like offshoring, has increased the need to ensure any measures taken do not jeapordize a company's competitiveness.

In this article, we consider numerous options for improving the sustainability of manufacturing operations for office furniture partitions, from the perspective of reducing emissions of volatile organic compounds (VOCs). Volatile organic compounds are organic hydrocarbons that can volatize to form organic vapour in air, and constitute the most significant environmental impact of the wood furniture industry. Recognized as significant indoor contaminants, VOCs often have indoor concentrations several times higher than outdoors and are often attributed to be the cause of "sick-building syndrome." The objective of this investigation is to identify sustainable measures for reducing VOC emissions in the wood furniture industry and to apply these concepts to the manufacturing of office furniture partitions so as to enhance the sustainability of that process.

In this article, current VOC emission levels are assessed in the wood furniture industry and in typical manufacturing plants for office partitions. Also, current legislation and regulations are examined regarding VOC emissions in Ontario. Potential sustainability measures are identified, such as improved management practices, equipment and production process modifications, recycling, reuse and abatement technologies. An evaluation methodology is described that seeks to balance options for improving sustainability by reducing VOC emissions in a manner that is acceptable to industry, accounting for technical, environmental, economic and other considerations. The results are expected in general to help identify balanced approaches to enhancing the sustainability in a manufacturing operation, and more specifically to provide input for a more comprehensive feasibility analysis of the measures that exhibit the greatest potential advantages. 


\section{Background}

Sustainability aspects of furniture manufacturing are discussed in this section. Furniture manufacturing and associated emissions are described, and the impact and prevention of VOC emissions are outlined. Air emissions for the wood furniture industry are also compared with air emissions for other industries.

\subsection{Furniture Manufacturing and Sustainability}

A strategic approach to advancing sustainability at Steelcase, a major office furniture manufacturer, has recently been described [1]. The approach is intended to minimize the company's environmental footprint, and involves the use of environmentally responsible facilities and processes, eco-sensitive products and materials that can be re-used and recycled, and informing and engaging stakeholders. An objective of the approach is to share learning with others in the industry.

Materials selection issues for sustainable product design have been investigated and applied to wood-based furniture [2]. The environmental impact is assessed of the materials and processes typically used in the wood-based furniture manufacturing, with a life cycle assessment methodology applied to different kinds of wood based boards, surface and edge coverings, and their respective manufacturing processes.

The use of materials for sustainability in interior architecture and design has recently been investigated [3]. That study points out that the environmental impacts during manufacturing are significant when selecting materials and products for interior environments, as are issues related to consumption, the practice of specification for the use of materials and products, the impacts of indoor air quality, and end-of-life options. The article addresses how interior designers and architects can address related environmental by specifying materials and products, while understanding the life cycle impacts of their designs as well as the materials they use, for domestic and commercial applications.

More generally, green chemistry has been cited as an important tool for addressing the challenges for sustainability in manufacturing [4]. Green chemistry involves the design and development of chemical products and processes to reduce or eliminate the use and generation of substances hazardous to human health and the environment. The principles of the method are applicable to furniture manufacturing, and integrate sustainability into innovation.

\subsection{Furniture Manufacturing and Emissions}

Canada's furniture industry is the second largest exporter in the world, with $52 \%$ of production being shipped outside Canada [5]. Canadian furniture companies face competitive pressures domestically and globally. This competition, combined with worldwide trends in environmental protection and due diligence, is causing companies to consider the environmental impacts of their products and to take steps to reduce them. Market forces and environmental regulations have led to the development of sustainability and pollution prevention programs. Pollution prevention is defined by the Ontario Ministry of the Environment as any action that reduces or eliminates the creation of pollutants or wastes at the source. Pollution prevention and sustainability are achieved through 
activities that promote, encourage or require changes in the basic behavioural patterns of industrial, commercial, institutional, community and government generators or individuals.

The applicability has been investigated of pollution regulations to the furniture industry, with a focus on the location decisions of firms and industries [6]. The study shows how regulations can create uncertainty within the industry, and cause some firms to relocate to less regulated jurisdictions while others adjust to environmental regulations through product and process innovations.

Environmental impacts associated with furniture are limited during use but more associated with production and disposal. One method proposed to promote environmentally sound furniture design and motivate furniture manufacturers to make products with reduced environmental impacts, is green public procurement [7]. The method notes that requirements and criteria for furniture purchasing thus need to target environmental aspects that have the most influence and could lead to the greatest environmental benefits. But the focus is on understanding the extent to which environmental aspects of furniture are taken into consideration in public purchasing.

Wastes from manufacturing furniture impact land, air and water. One of the most significant environmental impact of the wood furniture industry is air pollution in the form of volatile organic compounds (VOCs), organic hydrocarbons that can volatize to form organic vapour in air. VOC emissions top all pollution categories in the wood furniture industry, with toluene, methanol and xylene leading all other chemicals [8].

\subsection{Impact and Prevention of VOC Emissions}

VOCs are carbon containing substances that rapidly evaporate. VOCs emitted to the atmosphere contribute to acid rain and the greenhouse effect, and react with oxides of nitrogen in the presence of sunlight to form ozone in the lower atmosphere. Low-level ozone is a component of photochemical smog, which is a persistent air quality problem in many parts of the world. The environmental impact of smog can have effects on both health and property, while high levels of ground-level ozone can damage plants, cause respiratory irritation and create haze. Agricultural losses from ground-level ozone have been estimated to be nearly \$70 million in Ontario and \$9 million in the Lower Fraser Valley of British Columbia [9].

Green design has been proposed for sustainable buildings [10]. In that work, low-VOC interior finishes and paints are encouraged. Other design factors such as site sensitivity, resource efficiency, energy-saving technologies, and conscientious material use are also considered.

Various other approaches can be used to reduce indoor air VOC pollution. For example, the benefits have been investigated of potted plants in reducing VOC levels in offices [11]. The findings demonstrate that potted plants can provide an efficient, self-regulating, low-cost, sustainable, bioremediation system for indoor air pollution, which can effectively complement engineering measures to reduce indoor air pollution, and hence improve the well-being of people and their productivity.

Regulatory drivers are important in the development of VOC reduction initiatives in many industrial sectors. Since the 1990s, Canada and the US have significantly reduced emission of VOCs. For example, Ontario stated VOC reduction objective of $45 \%$ based on the 1990 levels by the year 2010 [12]. 
Guidelines have been developed for the wood furniture sector by the Canadian Council of Ministers of the Environment (CCME) to provide a basis for provincial and regional governments to develop regulatory or non-regulatory management instruments to achieve their own specific reduction objectives.

\subsection{Comparison of Air Emissions for the Wood Furniture and Other Industries}

Annual emissions of selected pollutants for various industries in the United States for 1995 are listed in Table 1. The pollutants considered include:

- carbon monoxide (CO),

- nitrogen dioxide $\left(\mathrm{NO}_{2}\right)$,

- particulate material of 10 microns or less (PM10),

- total particulate matter (PT),

- sulphur dioxide $\left(\mathrm{SO}_{2}\right)$ and

- VOCs.

Carbon dioxide is not considered even though it is the main greenhouse gas and considered a significant contributor to climate change, because it is an inherent product of carbon combustion, rather than a conventional pollutant. For comparative purposes, total annual emissions in the entire U.S. for these pollutants are also listed.

Industrial sources of air pollution are frequently exceeded by sources in the residential, commercial, agricultural and transportation sectors [13]. This is demonstrated in cities such as Toronto or Los Angeles, where air quality deteriorates closer to the city core even though most industrial sources are outside the city centres. Industrial sources, however, are more noticeable because emissions are concentrated and discharged through stacks.

For the wood furniture industry, VOC emissions are seen in Table 1 to be the most significant contributors to air pollution in terms of quantity (54 kilotonnes per year). VOC emissions normally represent the majority of air pollutant releases in the manufacturing of office furniture partitions. The wood furniture industry is the ninth largest contributor of VOC emissions in the U.S.

Table 1. Annual atmospheric emissions (in kilotonnes) for industry in the U.S for selected pollutants*.

\begin{tabular}{lrrrrrrr}
\hline \multicolumn{1}{c}{ Industry } & VOC & CO & NO $_{2}$ & PM10 & PT & SO $_{2}$ & Total \\
\hline Chemicals & & & & & & & \\
$\quad$ Petroleum refining & 280 & 380 & 346 & 17 & 34 & 588 & 1642 \\
$\quad$ Organic and inorganic chemicals & 230 & 284 & 314 & 28 & 75 & 285 & 1216 \\
$\quad$ Rubber, miscellaneous plastic & & & & & & & \\
$\quad$ products & 128 & 2 & 11 & 2 & 5 & 27 & 174 \\
$\quad$ Subtotal & 639 & 666 & 670 & 47 & 114 & 899 & 3032 \\
Wood products & & & & & & & \\
$\quad$ Pulp and paper & 88 & 566 & 357 & 32 & 104 & 309 & 1461 \\
$\quad$ Wood furniture and fixtures & 54 & 2 & 3 & 2 & 3 & 2 & 65 \\
$\quad$ Lumber and wood products & 38 & 113 & 39 & 13 & 58 & 8 & 268 \\
$\quad$ Subtotal & 179 & 681 & 399 & 47 & 164 & 319 & 1793 \\
\hline
\end{tabular}


Table 1. Cont.

\begin{tabular}{lrrrrrrr}
\hline Metals & & & & & & & \\
$\quad$ Iron and steel & 75 & 1378 & 126 & 39 & 75 & 216 & 1905 \\
$\quad$ Nonferrous metals & 25 & 407 & 51 & 18 & 20 & 338 & 859 \\
$\quad$ Fabricated metals & 93 & 4 & 15 & 1 & 3 & 4 & 119 \\
$\quad$ Subtotal & 192 & 1789 & 192 & 58 & 99 & 558 & 2883 \\
Mining and other base materials & & & & & & & \\
$\quad$ Mining & 3 & 9 & 52 & 90 & 279 & 96 & 531 \\
$\quad$ Stone, clay, glass, concrete & 28 & 53 & 307 & 68 & 156 & 308 & 916 \\
$\quad$ Subtotal & 30 & 62 & 359 & 157 & 435 & 404 & 1447 \\
Other manufacturing and processes & & & & & & & \\
$\quad$ Printing & 93 & 8 & 4 & 0 & 1 & 2 & 107 \\
$\quad$ Motor vehicle bodies, parts, & & & & & & & \\
$\quad$ accessories & 92 & 32 & 22 & 2 & 12 & 23 & 182 \\
$\quad$ Dry cleaning & 7 & 0 & 0 & 0.0 & 0 & 0 & 7 \\
$\quad$ Electronics & 4 & 0 & 1 & 0 & 0 & 1 & 7 \\
$\quad$ Subtotal & 195 & 40 & 27 & 3 & 13 & 25 & 303 \\
Total for country & 21,137 & 88,178 & 21,228 & 41,277 & 71,123 & 19,867 & 26,281 \\
\hline
\end{tabular}

* Adapted from AIRS database of U.S. EPA, based on data for 1995 [8].

\section{Processes in Office Panel Manufacturing and VOC Emissions}

In a typical manufacturing operation for partition panels, medium density fibreboard (MDF) is milled to specific shapes (trims) using industrial wood working equipment. Veneer is applied to the trims using a hot melt adhesive. The trims are coated by primer and paint or by stain, sealer and lacquer. The coating material is solvent-based and is applied manually or automatically in ventilated booths. The parts are air-dried on heating racks or in an air tunnel or by baking in an industrial oven. Sheets of acoustical fibreglass are cut and fitted with metal clips, which are adhered to the panels using a polyester resin. The product is sprayed with an adhesive, and moved to an assembly area where fabric is applied. Aluminium frames are assembled and the trims and panels are applied to the frames. Three main processes in the overall manufacturing operation contribute to VOC emissions:

- Surface coating. Surface coating and painting protect surfaces, inhibit corrosion and rusting, enhance weatherability and durability, and provide resistance to harsh environments, abrasion, scratching and staining [14]. In the furniture industry, surface coatings are mainly used to enhance the aesthetics of wood surfaces. Coating material typically consists of solutions of organic resins, organic and inorganic colour pigments, stabilizers and extenders [14]. The organic solvent is used for transporting the components and for giving the liquid properties (e.g., flow characteristics, viscosity, surface tension) necessary for consistent application of coating layers [14]. Fugitive evaporation during drying of organic solvents leads to the main environmental emissions from the wood furniture industry. In addition, emissions result from coating materials that do not bind to the substrate, wastes generated during equipment cleaning or colour changeovers, and the removal of coating material from defective parts. 
- Adhesive application. Common adhesives used in the furniture industry include polyvinyl acetate, hot melts, urea formaldehyde and pressure sensitive adhesives. While not a significant source of releases, gluing operations are a source of atmospheric VOC emissions. Adhesives are used in such operations as applying metal clips to fibreglass, veneer to MDF, fabric to fibreglass and polyvinyl chloride, and solid wood end caps to MDF.

- Cleaning. In wood coating operations, industrial solvents are used to clean the piping in finishing application equipment, manufacturing booths and glue application equipment, and to remove coating from non-conforming parts [8]. Finishing application equipment must be flushed to clean residual material each time there is a colour change, and when the equipment is idle for a long period of time. Spray guns, storage pots and fluid lines must be cleaned in a spray coating operation. Roller and spray bars must be cleaned in a roller coating operation. Spray equipment is cleaned by pumping clean solvent through the system into a container. Spray nozzles and spray guns are soaked in solvent for cleaning.

\section{Determination of Base VOC Emissions for Office Panel Manufacturing}

Emission rates are best determined by performing source testing but, since air-sampling techniques are costly, emissions are often estimated using a mass balance approach [15]. That is the approach used here.

\subsection{Mass Balance Approach for Base Emissions}

The mass balance approach is a widely accepted and cost-effective method of estimating VOC emissions[12]. This approach is used here to calculate emissions because VOC and material usage data are often available. A mass balance expresses the mass of a compound emitted in terms of other mass flows and accumulations in the system.

The mass emitted in an unconstrained manner $m_{\mathrm{e}}$ can be expressed as:

$$
m_{\mathrm{e}}=m_{\mathrm{i}}-m_{\mathrm{p}}-m_{\mathrm{a}}-m_{\mathrm{c}}
$$

where $m_{\mathrm{i}}$ denotes the mass of the input stream, $m_{\mathrm{p}}$ the mass of the finished product, $m_{\mathrm{a}}$ the mass accumulated in the system, and $m_{\mathrm{c}}$ the mass captured for recovery or disposal.

\subsection{VOC Emissions in Plant}

In the present investigation, the main VOC sources are considered to be coatings and adhesives, which consist of resins, pigments, additives, solvents, diluents and thinners. Resins, pigments and additives are the solid (non-volatile) portion of the coating or adhesive, while solvents, diluents and thinners are the volatile portion, which evaporate during the mixing, application and curing of the coating or adhesive [15].

During manufacturing, it is assumed that there is no accumulation of coating or adhesive in the system, since any coating that is deposited on the equipment is removed during cleaning and captured for waste disposal or the volatile portion will evaporate. Typically, 15-20\% of coating and cleaning 
materials for finishing material like trims and 3-5\% of upholstery-related adhesive and cleaning materials used in the clip application process are collected for waste disposal. All other volatiles in the material are assumed are emitted to the atmosphere.

The total VOC emissions $E_{V O C}$ (in $\mathrm{kg}$ ) from coating and adhesive applications are calculated as follows[15]:

$$
E_{V O C}=Q \rho d
$$

where $Q$ denotes the total annual consumption of material $(\mathrm{L}), \rho$ the density of the material $(\mathrm{kg} / \mathrm{L})$ and $d$ the fractional VOC content by weight in the material. Figure 1 summarizes the annual VOC emissions by material type and plant area for a typical plant, using the mass balance approach. The VOC emissions for each material used in a plant are based on examinations of several actual plants. The typical facility is assumed to produce 200,000 panels annually, and to have a total floor area of approximately $15,000 \mathrm{~m}^{2}$.

Figure 1. Breakdown of annual VOC emissions by plant area and operation.

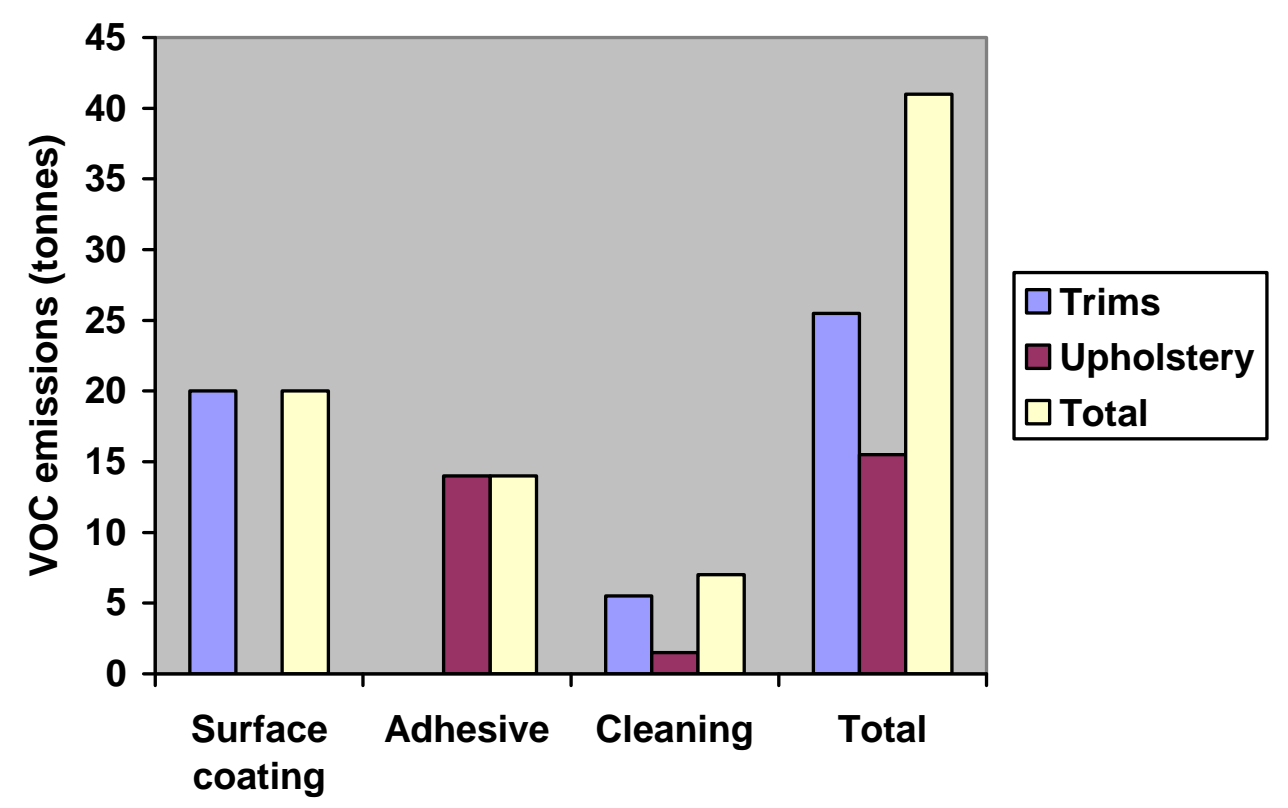

\section{Relevant Sustainability Measures}

Various measures to reduce emissions of volatile organic compounds sustainably from the office partition manufacturing operation are considered. A pollution prevention focus is followed.

\subsection{Best Management Practices}

The simplest and least expensive way to reduce pollution is to implement best management practices (BMPs). BMPs are practices that a government or planning agency determines to be the most effective and practical means of reducing the amount of pollution generated by point or non-point sources. The BMPs considered are as follows: 
- Standard operating procedures. The correct operation of equipment can help in enhancing sustainability and preventing pollution. Written standard operating procedures should be readily available which describe the tasks an operator must perform, safety parameters, and safety precautions for operations and maintenance activities [16]. Standard operating procedures for manual spray operations can improve transfer efficiencies, thereby reducing the overall contribution to air emissions. The following guidelines should be followed when operating manual spray equipment [17]: maintain 50\% overlap between spray patterns, hold spray gun perpendicular to the part to be coated to prevent inconsistencies in coating depth, maintain 15-20 cm distance between spray gun and workpiece, trigger the gun at the beginning and end of each pass, and avoid excessive air pressure for coating atomisation.

- Preventative maintenance. Programs should be established for the regular maintenance, inspection and testing of equipment to ensure that it is fit for the purpose for which it was designed [16]. Routine maintenance of spray guns, fluid lines and pumps can prevent equipment from breaking down and leaking. Also, accurate record keeping of equipment checks, repairs and cleaning may reduce the likelihood of accidental releases to the environment.

- Employee training and involvement. Personnel need to be made aware of the contribution of emissions generated outside the primary coating operation, which are comparatively small for furniture manufacturing, and be involved in reducing VOC emissions. Training should be provided in operation of production equipment to minimize energy use and material waste, proper material handling to reduce waste and spills, detecting and minimizing material losses to air, land and water, emergency procedures to minimize lost materials during accidents, and solvent conservation and management.

- Production scheduling. The way that orders are scheduled can impact the amount of waste generated. Reduced emissions can be achieved when creating the master production schedule using the following guidelines: optimize batch size to reduce frequency of cleaning, and schedule colour sequence to minimize cleaning requirements (light to dark colours).

- Inventory management. The wide range of chemicals used in the wood furniture industry requires an efficient material tracking program to ensure that older chemicals are not needlessly discarded. A computerized inventory system can assist in controlling and tracking materials to reduce overstocking. Using inventory on a first-in first-out basis reduces the volume of waste generated from expired chemicals [8]. Also, more accurate forecasting of material requirements for production reduces the frequency of material expiration due to overstocking. Just-in-time ordering, characterized by small delivery lot sizes, reduces the total volume of chemical stored at the facility, which reduces the likelihood of accidental spills [18].

- Scrap reduction. Statistical process control can control process capabilities and quality. Statistical methods help monitor and predict process variations, and minimize the occurrence of defective products. These methods can reduce overall VOC emissions. In 
addition, design of experiment, a structured method for determining the relationship between factors affecting a process and the output of that process, can ensure the repeatability and reduction of process variations.

\subsection{Paint Equipment Modifications}

Manufacturers can change paint application equipment to improve transfer efficiencies and reduce waste. Spray equipment and spray patterns both influence transfer efficiency. The following paint equipment modifications are considered:

- High volume, low pressure spray guns. High volume, low pressure (HVLP) spray application guns limit the air flow and convert high pressure, low volume air into low pressure, high volume air. Air is only used when the gun is operated so 'bounce back' and 'overspray' are reduced. Bounce back refers to coating material which hits the substrate but does not adhere and overspray refers to coating material which misses the substrate when sprayed. Transfer efficiency and the working environment are improved by decreasing bounce back and overspray [19]. Most office partition manufacturing utilizes conventional spray guns which operate at high pressures and have low transfer efficiencies.

- Spray pattern optimization. Spray patterns for automated spray equipment can be optimized for the size and geometry of the part to be coated. In addition, it is important to ensure that air and fluid pressure settings are correct. Although increasing the pressure is often thought to increase spray rate and efficiency, operating at too high a pressure increases spray bounce back, excessively wears machine components and increases compressed air demand and energy consumption [20].

- Air purge of paint lines. Using compressed air to clean solvent lines can significantly reduce solvent consumption. A colour change manifold can force compressed air through pump lines, whereby air is gently forced through the line to utilize paint in the line and then air is input to empty the line and a small quantity of solvent is used to clean the lines prior to switching to the new colour.

\subsection{Production Process Modifications}

The production process modifications considered are manufacturing changes that substitute less toxic materials or reduce waste generation (e.g., UV-based coatings, water-based coatings, high solids adhesives). The modifications considered to the production process follow:

- Water-based surface coatings. Water-based coatings, which are neither flammable nor toxic, can replace solvent based coatings and contain a small fraction of the VOC content of traditional solvent-based coatings. A small amount of solvent is needed for softening the resin [19]. Some office partition manufacturers have implemented a water-based finish on some of their wood furniture. Water-based systems can help meet anticipated VOC emission regulations, decrease fire hazards, and improve working conditions, colour consistency, and brushability and adhesion of stain. 
- Hot melt backwrapping adhesive. The glue used to apply the fabric to the back edge of fibreglass panels (referred to as backwrapping) contains a small percentage of toluene, which facilitates mixing of the activator and the adhesive. Utilizing an alternative adhesive, such as a hot melt which is solvent-free, can eliminate VOCs. The glue is melted and then pumped through a heated hose where it is deposited onto the substrate, cools and hardens.

\subsection{Product Redesign}

Sustainability and pollution prevention is usually most effective during the planning, design and development of a product or process [21]. Design changes to prevent pollution should not adversely affect function [17]. Some measures to consider for improving environmental aspects when designing products include use of renewable and recycled materials, use of fewer toxic solvents, reuse of scrap and excess materials, reduction of packaging, and production of more durable goods. The redesigns considered are as follows:

- Mechanical clip attachment. Panel manufacturing often utilizes a polyester resin to adhere metal clips to tiles made of fibreglass or other materials for the application to frames, usually made of metal. The metal clips engage with U-clips that have been fastened to the inside of the frame. The equipment that dispenses the polyester resin is cleaned using products like acetone. This process contributes significantly to VOC emissions, increases the fire hazard, is odorous and can cause health problems. Redesigning to use a clip with a mechanical attachment can reduce the requirement for this hazardous process. The mechanical clip can be designed to attach to the tile without adhesives and snap directly onto the frame. Switching to a mechanical clip affects the cost of the panel by eliminating the material cost of the resin, catalyst, solvent and U-clips as well as the labour cost to apply the resin. The panel and tile connector need to be redesigned to accept mechanical clips, adding costs.

- Cease painting non-visible parts. Parts that are not visible to the customer may not require surface coating. Aluminium and plastic components on furniture partitions are coated for aesthetic purposes only, as the surface coating does not provide additional protection from damage or corrosion. Generally, the application of coating materials contributes to VOC emissions, with the exception of some powder-coated and waterbased finishes. In office panels, some parts are typically not visible to the customer, like upper horizontal and vertical frame members and corner posts. Removing the painting process for these parts reduces VOC contribution of the product for the manufacturing (unless done by a supplier external to the plant). In this study, it is assumed that these parts are coated at an external supplier, as that is often the case.

\subsection{Recycling and Reuse}

The only recycling operation considered is solvent recycling. Recycling spent solvent eliminates the need to transfer solvent during hazardous waste disposal pickup (reducing the opportunity for spills), 
reduces the demand to manufacture virgin solvent and reduces the volume of hazardous waste generated for disposal. Overspray from surface coating operations and dirty solvent from cleaning operations can be distilled to separate the waste coating material from the solvent. The solvent can then be reused for cleaning operations.

\subsection{Abatement Technologies}

Two abatement technologies are considered for the partition manufacturing plant:

- Oxidation. The most widely employed type of VOC destruction is currently thermal or catalytic oxidation, which raises the temperature of the exhaust gas above $800^{\circ} \mathrm{C}$ to destroy organic compounds. Heat recovery is incorporated in most systems to reduce energy use. Catalytic incineration operates at around $350^{\circ} \mathrm{C}$ with organic compounds being oxidized in a catalytic bed [19].

- Biological abatement. Biological treatment represents a more cost-effective method for the destruction of VOCs. The treatments have similar capital and lower operating costs than oxidation. Biofiltration is a control technology that sends exhaust gas through a filter of micro-organisms, which use the organic matter in the air stream as a food source [14]. Biotreatments are able to degrade a wide range of organic solvents.

\section{Methodology for Assessing and Balancing Sustainability Measures}

To prioritise sustainability and pollution prevention measures and to identify the most advantageous, the measures defined in the previous section are examined according to several criteria. The criteria deemed most relevant for the present manufacturing operation were developed based on examinations of several manufacturers, and are as follows:

- Economics. Many factors affect economics, which itself consists of several aspects. Four subcriteria related to costs are deemed important:

o Raw material costs

o Waste disposal costs

o Capital costs

o Operating costs

- Resources. All resource requirements were grouped within this category.

- Environment. Only VOC emissions were considered since that is the focus of this study. Two subcriteria related to the environment are considered:

o Internal VOC emissions (fugitive and point source emissions within the facility) oExternal VOC emissions (raw material manufacturing and waste disposal emissions)

- Quality. The focus of this category was on quality of the final product.

- Health and safety (H\&S). Only employee health and safety was considered. The health and safety of the public were not deemed to be significantly at risk due to the 
operations of the manufacturing facility, so public health and safety was not considered as a weighting criterion.

- Time. The focus of this category was on implementation time for the changes. Other time factors were not deemed significant for purposes of weightings.

The weighted-sum method is used for screening and rating pollution prevention measures, as suggested by the Ministry of the Environment [17]. The following two key steps are involved in this method:

- First, each criterion is given a weight based on its perceived importance. Typical manufacturers in this industry were examined and it was observed that many place 1) a high emphasis on employee safety, cost improvement and product quality, so these are given a higher value here, and 2) a lower emphasis on capital costs, implementation time and external VOC reductions, so these are given a lower value here. The weightings for the criteria and subcriteria considered here are listed in Table 2.

- Second, each measure is then rated based on how it impacts each criterion, using the rating scale in Table 3.

Table 2. Criteria weights.

\begin{tabular}{lcc}
\hline Criteria & Weight & $\begin{array}{c}\text { \% of total } \\
\text { weight* }\end{array}$ \\
\hline Economics & 16 & 42 \\
Raw material costs or use & 5 & 13 \\
Waste disposal costs & 4 & 11 \\
Capital costs & 3 & 8 \\
Operating costs & 4 & 11 \\
Resources & 3 & 8 \\
Resource requirements & 3 & 8 \\
Environment & 7 & 18 \\
Internal VOC emissions & 4 & 11 \\
External VOC emissions & 3 & 8 \\
Quality & 5 & 13 \\
Product quality & 5 & 13 \\
Health and safety & 5 & 13 \\
Employee health and safety & 5 & 13 \\
Time & 2 & 5 \\
Implementation time & 2 & 5 \\
Total & 38 & 100 \\
\hline
\end{tabular}

* Percentages may not add to totals due to round-off errors.

In examining the criteria weights in Table 2, note that the greatest weights are applied to economic factors, which account for $42 \%$ of the total weighting. Resources are often combined with economics since resource requirements often directly correlate with economics. The weight for economics and resources together is $50 \%$ of the total weight. Environment factors, a significant focus of the investigation, are assigned a combined weight of only $18 \%$. 
Establishing appropriate criteria weights is critical for sustainability measures, in that they must reflect not just the importance of sustainability factors but also other factors that industry considers important. If this balance is not adequately achieved, industry is not likely to implement the results of an assessment of sustainability options. From a general perspective, and often from an industry perspective, sustainability in its broader sense implies economic and social sustainability, as well as environmental sustainability. Hence factors like economics must be weighted reasonably. In addition, the impact ratings assigned to a criterion must be reasonable from an industry as well as a sustainability perspective. These points highlight that it is important to seek and act on the input of the industry being examined when establishing weights, and assigning impact ratings to the criteria. The weight of each criterion was developed here based on examinations of several manufacturers.

In the weighted-sum method, the total rating $R_{t o t}$ is determined using the information in Tables 2 and 3 . For a measure with criteria $1,2,3, \ldots n$, each having a corresponding weight $W_{1}, W_{2}, \ldots W_{n}$, the total rating $R$ can be expressed as follows using the individual criteria ratings for each measure $R_{1}, R_{2}$, $\ldots R_{n}$ :

$$
R_{t o t}=\sum_{j=1}^{n} R_{j} W_{j}
$$

Here, there the number of criteria considered is $n=10$.

Table 3. Possible ratings for criteria.

\begin{tabular}{lc}
\hline \multicolumn{1}{c}{ Rating } & Value \\
\hline High positive impact & 5 \\
Low positive impact & 4 \\
Minimal or no impact & 3 \\
Low negative impact & 2 \\
High negative impact & 1 \\
\hline
\end{tabular}

\section{Results}

The weighted-sum method described earlier is used for screening and rating VOC reduction measures. In that method, the rating for a particular criterion is multiplied by the weight of the criterion (listed in Tables 2 and 3). A measure's overall rating is the sum of the products of the rating times the weight of the criterion, according to Eq. 3 [17].

The results of applying the weighted sum method to rate the pollution prevention measures are presented in Table 4. The weights for the different criteria considered are also listed in Table 4, under each criterion. The maximum total rating is seen in Table 4 to be 190, which is achieved by summing for all the criteria the product of the criterion weights (38) and the maximum rating (5).

Only measures with an overall rating of 115 or greater are considered for a comprehensive feasibility analysis. Other measures may still be beneficial in other conditions, but are not considered further here. 
Table 4. Ratings for VOC reduction measures for various criteria based on the weighted sum method.

\begin{tabular}{|c|c|c|c|c|c|c|c|c|c|c|c|c|}
\hline \multirow[b]{3}{*}{$\begin{array}{l}\text { Measure } \\
\text { category }\end{array}$} & \multirow[b]{3}{*}{ Measure } & \multicolumn{10}{|c|}{ Criteria (and weight) } & \multirow[b]{3}{*}{$\begin{array}{l}\text { Total } \\
\text { rating }\end{array}$} \\
\hline & & \multicolumn{4}{|c|}{ Economics } & $\begin{array}{c}\text { Resource } \\
\text { s } \\
\end{array}$ & \multicolumn{2}{|c|}{$\begin{array}{l}\text { Envir- } \\
\text { onment }\end{array}$} & Quality & H\&S & Time & \\
\hline & & 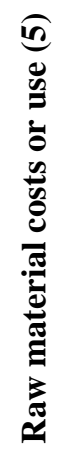 & 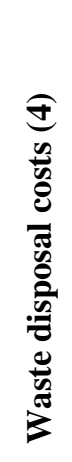 & 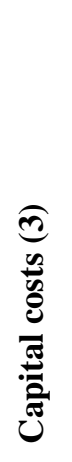 & 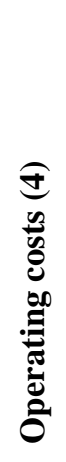 & 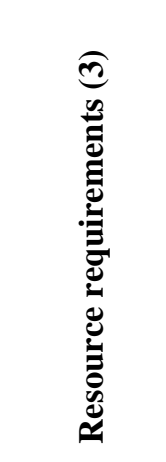 & 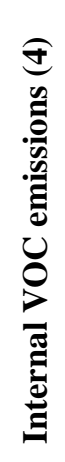 & 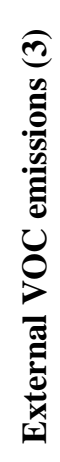 & 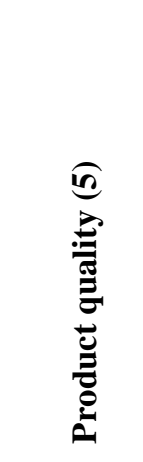 & 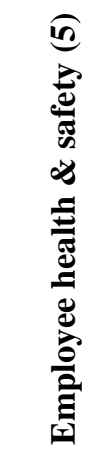 & 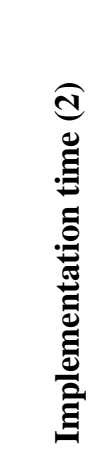 & \\
\hline \multirow[t]{6}{*}{$\begin{array}{l}\text { Best } \\
\text { management } \\
\text { practices }\end{array}$} & $\begin{array}{l}\text { Standard } \\
\text { operating } \\
\text { procedures }\end{array}$ & 4 & 3 & 3 & 3 & 3 & 4 & 3 & 3 & 4 & 4 & 130 \\
\hline & Employee training & 4 & 3 & 3 & 3 & 3 & 4 & 3 & 3 & 4 & 4 & 130 \\
\hline & Scrap reduction & 4 & 3 & 3 & 3 & 2 & 4 & 3 & 5 & 3 & 2 & 128 \\
\hline & $\begin{array}{l}\text { Preventative } \\
\text { maintenance }\end{array}$ & 3 & 3 & 3 & 2 & 3 & 4 & 3 & 3 & 4 & 4 & 121 \\
\hline & $\begin{array}{l}\text { Production } \\
\text { scheduling }\end{array}$ & 3 & 3 & 3 & 3 & 3 & 4 & 3 & 3 & 3 & 2 & 116 \\
\hline & $\begin{array}{l}\text { Inventory } \\
\text { management }\end{array}$ & 3 & 3 & 3 & 3 & 3 & 4 & 3 & 3 & 3 & 2 & 116 \\
\hline \multirow{3}{*}{$\begin{array}{l}\text { Equipment } \\
\text { modifications }\end{array}$} & HVLP guns & 3 & 3 & 2 & 2 & 3 & 4 & 3 & 3 & 3 & 3 & 111 \\
\hline & Air purge & 4 & 3 & 2 & 2 & 3 & 4 & 3 & 3 & 3 & 3 & 116 \\
\hline & $\begin{array}{l}\text { Spray pattern } \\
\text { optimization }\end{array}$ & 3 & 3 & 3 & 2 & 3 & 3 & 3 & 2 & 3 & 3 & 105 \\
\hline \multirow[t]{2}{*}{$\begin{array}{l}\text { Process } \\
\text { modifications }\end{array}$} & $\begin{array}{l}\text { Hot melt for } \\
\text { backwrapping }\end{array}$ & 3 & 3 & 2 & 4 & 2 & 4 & 3 & 5 & 4 & 2 & 129 \\
\hline & $\begin{array}{l}\text { Water based } \\
\text { finishes }\end{array}$ & 1 & 5 & 2 & 3 & 2 & 5 & 3 & 2 & 5 & 1 & 115 \\
\hline \multirow{2}{*}{$\begin{array}{l}\text { Product } \\
\text { redesign }\end{array}$} & Mechanical clip & 5 & 4 & 1 & 4 & 1 & 4 & 3 & 4 & 4 & 1 & 130 \\
\hline & $\begin{array}{l}\text { Cease painting of } \\
\text { non-visible parts }\end{array}$ & 5 & 3 & 3 & 3 & 5 & 3 & 5 & 2 & 3 & 3 & 131 \\
\hline $\begin{array}{l}\text { Recycling } \\
\text { and reuse }\end{array}$ & Solvent recycling & 4 & 5 & 2 & 2 & 2 & 3 & 4 & 3 & 3 & 2 & 118 \\
\hline \multirow[t]{2}{*}{ Abatement } & $\begin{array}{l}\text { Biological } \\
\text { abatement }\end{array}$ & 3 & 3 & 1 & 2 & 1 & 5 & 1 & 3 & 3 & 1 & 96 \\
\hline & Oxidation & 3 & 3 & 1 & 1 & 1 & 5 & 1 & 3 & 3 & 1 & 92 \\
\hline
\end{tabular}




\section{Discussion of Sustainability Measures Relative to Evaluation Criteria}

The rationales for the assigned ratings in Table 4 are discussed in the following subsections. Explanations are not provided where there is minimal or no impact on the criterion.

\subsection{Best Management Practices}

In general, BMPs maintain product quality, have low capital and operating costs and short implementation times, and have been used successfully in industry. But they do not reduce VOC emissions as significantly as other measures, and do not result in significant waste disposal or raw material savings.

\subsection{Equipment Modifications}

Three equipment modifications were determined to be potentially worthwhile:

- HVLP guns. Purchasing and installing HVLP spray guns reduces slightly VOC emissions. The main negative impacts are the capital expenditure required to purchase the equipment and the likely decrease in operating efficiency.

- Spray pattern optimization. The shape of the product to be coated is relatively constant since the different trim types normally exhibit only minor differences in profile. Preliminary observations indicate that adjusting spray pattern according to product shape results in minimal reductions in VOC emissions, raw material usage and waste disposal costs. Manual spray pattern adjustments reduce efficiency since more work time is required to adjust the spray patterns based on the production schedule. Automated spray pattern adjustments require a significant capital investment. In addition, frequent machine adjustments increase the risk of parts becoming defective.

- Air purge. An air purge system decreases VOC emissions and raw material costs, since less solvent is required to purge the fluid lines.

\subsection{Process Modifications}

Two modifications of the process were determined to be worth considering further:

- Water-based finishes. The implementation of a water-based coating system reduces significantly VOC emissions and hazardous waste disposal costs since the solvent content of the coatings is reduced. In addition, the reduced risk of explosion and exposure to solvent vapours improves employee health and safety. The major impediment to implementation is the high cost of water-based coatings.

- Hot melt backwrapping. The implementation of a hot melt backwrapping system reduces slightly VOC emissions as typical glue materials contain less than $3 \%$ toluene. The main advantage of hot melt glues are their resistance to UV radiation, as the current glue discolours over time when exposed to UV radiation. Another benefit is a decrease in operating costs since hot melt glues do not require ventilation. Currently three spray booths are dedicated to ventilation for the backwrapping adhesive. 
Removing these spray booths eliminates the cost of booth maintenance, filter pads, electricity to run the fans and natural gas to heat plant make-up air.

\subsection{Product Modifications}

Two potential product modifications were determined to merit further consideration:

- Mechanical clip. The mechanical clip modification reduces the demand for polyester resin, cadox and acetone, reducing VOC emissions and material and disposal costs. The major obstacles for this measure are high capital and development costs and a long implementation time.

- Cease painting of non-visible parts. Purchasing parts without coatings reduces external VOC emissions and the cost of the part, and requires minimal internal resources.

\subsection{Recycling and Reuse}

Solvent recycling was determined to be potentially of significant benefit. Waste disposal and material expenses are reduced by distilling dirty cleaning solvent. The disadvantages are capital funding, operating costs, internal resources and implementation time.

\subsection{Abatement}

Thermal oxidation and biological abatement, which are effective end-of-pipe solutions to VOC emissions, were determined to be potentially of significant benefit. These processes have high operating and capital costs.

\section{General Discussion}

The screening performed here suggests that several measures have significant potential for reducing VOC emissions in a sustainable and acceptable manner. These measures are best management practices, air purge of paint lines, water-based finishes, hot melt backwrapping, cease painting nonvisible parts, mechanical clip attachment, and solvent recycling. The initial assessment suggests that it would likely be advantageous for manufacturers of office panels to undertake several measures to enhance sustainability and prevent pollution. The measures can help the office furniture partition manufacturing industry improve its sustainability in environmental as well as economic ways. In addition to the direct benefits, many of the measures provide intangible and indirect benefits resulting from the pollution prevention measures.

The most advantageous measures depend on the particular circumstance, and their selection requires a more comprehensive and detailed feasibility assessment.

Such a feasibility analysis appears to be merited to help determine which measures are technically, environmentally and economically feasible. Such a feasibility assessment is the subject of ongoing research. 


\section{Conclusions}

This case study has demonstrated that several options exist for reducing volatile organic compound emissions in manufacturing office furniture partitions, and thereby enhancing the sustainability of that industrial operation. Sustainability has been considered from the perspective of factors like economics, environmental impact, quality, health and safety, as such factors are all considered important by industry. It appears that it would be advantageous for manufacturers of office panels to evaluate the feasibility of these measures for their operations, and then to implement the most appropriate ones. The results are intended to be balanced so as to improve their acceptability to industry in efforts to improve sustainability of manufacturing operations, and likelihood of adoption. It may be worthwhile to apply advanced methods of assessment, like exergy analysis [22], in future research to enhance the sustainability of the process further. More generally, the results are likely extendable to other operations in the wood furniture industry, and thus could help in improving sustainability more broadly.

\section{Acknowledgements}

Financial support was provided by the Natural Sciences and Engineering Research Council of Canada. This work is based in part on F.S. Luisser's 2004 project, performed under the supervision of M.A. Rosen in the Environmental Applied Science and Management master's program at Ryerson University, Toronto.

\section{Nomenclature}

$d \quad$ VOC content by weight in a substance

E emission mass

$m$ mass

$n \quad$ number of criteria

Q total volume of material used

$R \quad$ criterion rating

$W$ criterion weight

$\rho$ density

\section{Subscripts}

$\begin{array}{ll}a & \text { accumulated } \\ c & \text { captured } \\ e & \text { emitted } \\ i & \text { input } \\ p & \text { product } \\ \text { tot } & \text { total } \\ \text { VOC } & \text { volatile organic compound }\end{array}$

Acronyms

BMP best management practice

HVLP high volume, low pressure 
MDF medium density fibreboard

PM10 particulate matter of 10 microns or less

PT total particulate matter

UV ultraviolet

VOC volatile organic compound

\section{References}

1. Smith, A.W.; Rinard, D.A. A strategic approach to advancing sustainability at Steelcase. J. Organ. Excell. 2006, 25, 3-12.

2. Bovea, M.D.; Vidal. R. Materials selection for sustainable product design: a case study of wood based furniture eco-design. Material. Design 2004, 25, 111-116.

3. Máté, K. Using materials for sustainability in interior architecture and design. J. Green Build. 2007, 2, 23-38.

4. Manley, J.B.; Anastas, P.T.; Cue, B.W., Jr. Frontiers in Green Chemistry: meeting the grand challenges for sustainability in R\&D and manufacturing. J. Clean. Prod. 2008, 16, 743-750.

5. Canadian Council of Ministers of the Environment (CCME). Guidelines for the reduction of VOC emissions in the wood manufacturing sector. Winnipeg, Manitoba, Canada, 2004.

6. Thomas, W.F.; Ong, P. Locational adjustments to pollution regulations: the South Coast Air Quality Management District and the furniture industry. Econ. Dev. Q. 2004, 18, 220-235.

7. Parikka-Alhola, K. Promoting environmentally sound furniture by green public procurement. Ecol. Econ. 2008, 68, 472-485.

8. Canadian Council of Ministers of the Environment (CCME), Reducing Smog; Available online: http://www.ns.ec.gc.ca/epb/ccme/smog.html (accessed May 1, 2009).

9. Environmental Protection Agency (EPA). Profile of the Wood Furniture and Fixtures Industry. Washington DC, USA, 1995.

10. Thibaudeau, P. Integrated design is green. J. Green Build. 2008, 3, 78-94.

11. Wood, R.A.; Burchett, M.D.; Alquezar, R.; Orwell, R.L.; Tarran, J.; Torpy, F. The potted-plant microcosm substantially reduces indoor air VOC pollution: I. office field-study. Water Air Soil Pollut. 2006, 175, 163-180.

12. Evans, J.R. Applied Production and Operations Management. West Publishing Company: St. Paul, MN, USA, 1993.

13. Graedel, T.E.; Allenby, B.R. Industrial Ecology. Pearson Education: Upper Saddle River, NJ, USA, 2003.

14. Henry, G.; Heinke, G. Environmental Science and Engineering. Prentice Hall: Upper Saddle River, NJ, USA, 1996.

15. Indiana Department of Environmental Management. Compliance Manual for Indiana's Wood Furniture Manufacturers, Indiana, USA, 2001.

16. Industry Canada. Business Information by Sector: Furniture. Available online: http://www.ic.gc.ca/ eic/site/ furniture-meuble.nsf/eng/Home (accessed June 22, 2006).

17. Ministry of the Environment, Ontario (MOE). Pollution Prevention Planning-Guidance Document and Workbook, Ontario, CA, USA, 1993. 
18. Ministry of the Environment, Ontario (MOE). Step by step guideline for emissions calculation, record keeping and reporting for airborne contaminant discharge, Ontario, CA, USA, 2001.

19. Organization for Economic Co-operation and Development (OECD). OECD Guiding Principles for Chemical Accident, Prevention, Preparedness and Response, France, 2003.

20. Rafson, H. Odor and VOC Control Handbook. McGraw-Hill: New York, NY, USA, 1998.

21. Miller, G.; Burke, J.; McComas, C.; Dick, K. Advancing pollution prevention and cleaner production: USA's contribution. J. Clean. Prod. 2008, 16, 665-672.

22. Dincer, I.; Rosen, M.A. Exergy: Energy, Environment and Sustainable Development. Elsevier: Oxford, UK, 2007.

(C) 2009 by the authors; licensee Molecular Diversity Preservation International, Basel, Switzerland. This article is an open-access article distributed under the terms and conditions of the Creative Commons Attribution license (http://creativecommons.org/licenses/by/3.0/). 